\title{
Ethnic diversity: South Asian ethnicity is associated with increased coronary artery bypass grafting mortality
}

Stephanie J. Brister, MD, FRCS(C), ${ }^{a}$ Zainulabedin Hamdulay, MS, MCh, ${ }^{a, *}$ Subodh Verma, MD, ${ }^{a}$ Manjula Maganti, MSc, ${ }^{\text {a }}$ and Michael R. Buchanan, $\mathrm{PhD}^{\mathrm{b}}$

From the Cardiovascular Surgery Division, ${ }^{\mathrm{a}}$ University Health Network, Toronto General Hospital, Toronto, Ontario, Canada, and McMaster University Health Sciences Center, ${ }^{\mathrm{b}}$ Hamilton, Ontario, Canada.

This study was supported by independent funds obtained from the Cardiovascular Division at the Toronto General Hospital.

Presented in part at the 77 th Scientific Sessions of the American Heart Association, New Orleans, La, November 7-10, 2004.

Received for publication Dec 14, 2005; revisions received May 2, 2006; accepted for publication May 17, 2006.

Address for reprints: Stephanie J. Brister, MD, FRCS(C), University Health Network, Toronto General Hospital, 4N472 Cardiovascular Surgery Division, 200 Elizabeth St, Toronto, Ontario M5G 2C5, Canada (E-mail: stephanie.brister@uhn.on.ca).

*Zainulabedin Hamdulay is currently at 601 Pride, 7 Bungalows, Andheri West, Mumbai 400 061, India.

J Thorac Cardiovasc Surg 2007;133:150-4

$0022-5223 / \$ 32.00$

Copyright $\odot 2007$ by The American Association for Thoracic Surgery

doi:10.1016/j.jtcvs.2006.05.068
Objective: South Asian ethnicity might result in a higher atherosclerotic vascular risk compared with white ethnicity. However, the effect of South Asian ethnicity on clinical outcomes after cardiac surgery is unknown. Thus, we determined whether South Asian ethnicity is a predictor of a poorer outcome after coronary artery bypass grafting.

Methods: We examined data from 6177 South Asian and white patients who underwent coronary artery bypass grafting at the Toronto General Hospital from January 1994 through June 2003 and used propensity score matching techniques to analyze 917 patients from each group in more detail. Patients were matched for age, sex, body surface area, left ventricular ejection fraction, New York Heart Association class, previous cardiac surgery, number of diseased vessels, and other factors. Independent predictors of operative morbidity and mortality were determined by means of multivariate logistic regression.

Results: Overall operative mortality was $1.8 \%$. Mortality was higher in South Asian patients than in white patients $(2.5 \%$ vs $1.1 \%, P=.02)$. Postoperative morbidity (eg, myocardial infarction, sepsis, sternal wound infection, postoperative hospital stay, and use of inotropes) also was higher in the South Asian group. In addition to the standard independent predictors of mortality, South Asian ethnicity was an independent predictor of mortality (odds ratio, 3.1; 95\% confidence interval, 1.4-6.8).

Conclusions: These data indicate that South Asian ethnicity per se is an independent predictor of a poorer outcome after coronary artery bypass grafting and suggest that ethnicity is a cardiovascular risk factor that should be considered when assessing clinical outcomes preoperatively before coronary artery bypass grafting or other interventional revascularization procedures.

$\mathrm{T}$ here is increasing evidence that ethnicity per se is an important determinant of overall atherosclerotic coronary artery disease. Specifically, a number of studies suggest that South Asian patients (namely persons originating from India, Pakistan, Bangladesh, and Sri Lanka) have a higher incidence of coronary heart disease (CHD) than white patients. ${ }^{1-5}$ It has been suggested that the higher incidence of CHD can be attributed, in part, to differences in insulin resistance, procoagulant plasma levels, homocysteine, and exercise. Ethnic diversity also appears to be an independent predictor of CHD risk when these factors are matched between the different ethnic groups. ${ }^{1-10}$

More than 500,000 revascularization procedures per year are performed in North America alone to restore blood flow to patients with CHD ${ }^{11}$ Coronary artery bypass grafting $(\mathrm{CABG})$ in particular, albeit successful for most patients, is associated with significant adverse side effects, the risk of which can be predicted preoperatively. ${ }^{12}$ The recent aforementioned studies concerning ethnicity raise the possibility that the risks of these adverse side effects vary according to ethnic origin. Thus, both 


\section{Abbreviations and Acronyms \\ $\mathrm{CABG}=$ coronary artery bypass grafting \\ $\mathrm{CHD}=$ coronary heart disease \\ MI = myocardial infarction \\ NYHA $=$ New York Heart Association}

morbidity and mortality might be higher in South Asian patients than in white patients after CABG. If so, ethnicity should be weighted as an independent predictor of potential risks before proceeding with these interventional procedures. Given the diversity in our Canadian population in general and the large South Asian population in Toronto in particular, we undertook to explore this issue in more detail. Our specific objective was to determine whether being of South Asian origin was an independent predictor of a poorer outcome after CABG.

\section{Materials and Methods \\ Patients}

All patients $(14,747)$ who underwent CABG at the Toronto General Hospital between January 1, 1994, and June 30, 2003, were analyzed to identify Canadian South Asian and white patients in our study. Patients were identified as South Asian or white by 2 independent assessors, one being South Asian and one being white, using both first and last name criteria. All patients whose first or last name was in doubt were excluded. In addition, all Mediterranean-sounding names (eg, Hispanic, Italian, and Greek) and nondistinctive names were excluded. Previous studies indicate that using both distinctive first and last name identification criteria has a $94 \%$ to $100 \%$ sensitivity and a $95 \%$ to $100 \%$ specificity. ${ }^{13-15}$ To confirm the rigor of those results, 883 of these patients (445 "white" patients and 438 "South Asian" patients, respectively) were randomly selected and sent a follow-up questionnaire by mail to confirm (or refute) their ethnic identity as determined by the independent assessors. This included asking each patient to specify whether they were white (Canadian or British descent), South Asian (Indian, Pakistani, Bangladeshi, or Sri Lankan), of a mixed race or other ethnic background (eg, Chinese or Afro-American). Patients were only included if both parents were of the same ethnic origin. The follow-up response was $61 \%$ for both groups, (270 "white" patients and 269 "South Asian" patients), thereby satisfying a sample size criteria with a $95 \%$ confidence level and a 5\% margin of error. The error rates in correctly identifying the ethnicity were $1.5 \%$ in the white group and $1.1 \%$ in the South Asian group. These error rates are consistent with those reported in the literature. ${ }^{13-15}$

\section{Study Protocol}

We performed a retrospective analysis of data collected prospectively on 1163 Canadian South Asian patients and 5028 Canadian white patients.

The overall characteristics of both groups were identified to ascertain preoperative group differences. Propensity score matching techniques were used to match patients between the South Asian and white groups because of the differences observed in preoperative group characteristics. The patients were matched for age, sex, body surface area, left ventricular ejection fraction, New York Heart Association (NYHA) class, recent history of angina or myocardial infarction (MI), previous cardiac surgery, number of diseased vessels, timing of surgical intervention, family history, diabetes, hypertension, preoperative stroke, peripheral vascular disease, shock, syncope, renal failure, and left main disease.

\section{Statistical Analysis}

All statistical analyses were conducted with SAS (Version 8.2) software for Windows. ${ }^{16}$ Data on preoperative, intraoperative, and postoperative variables were collected by a trained database management group. Categoric variables were analyzed by using $\chi^{2}$ analysis or the Fisher exact test and were expressed as percentages. Continuous variables that had normal distribution were analyzed by using the Student $t$ test, and variables that had nonnormal distribution were analyzed with the Wilcoxon rank test. All continuous variables were expressed as means \pm standard deviation.

The objective of this analysis was to match the South Asian and white populations on preoperative characteristics and then evaluate perioperative and postoperative outcomes between the matched groups. Propensity-matched scoring methods were used to match the patients from the 2 groups. ${ }^{17}$ Univariate comparisons were made between the unmatched and matched groups for categoric and continuous variables. Multivariate logistic regression methods were used to identify all independent predictors of hospital mortality between the matched populations. The results of the multivariable analysis are expressed as odds ratios and $95 \%$ confidence intervals.

Nine hundred seventeen (79\%) of the 1163 South Asian patients initially identified could be matched with 917 white patients.

\section{Results}

The overall preoperative characteristics of both patient groups are shown in Table 1. There were a number of marked differences between the South Asian and white patient populations. Generally, the South Asian patients were younger and smaller than the white population. Interestingly, fewer South Asian patients had a family history of CHD. Their histories of previous angina, MI, and congestive heart failure were similar.

The incidence of left main disease was lower in South Asian patients, but the proportion of Asian patients with triple-vessel disease or previous reoperation was comparable. Left ventricular function was comparable between South Asian and white patients, but a higher percentage of South Asian patients were identified as being in NYHA class III or IV.

In addition, a higher percentage of South Asian patients were diabetic.

To eliminate the bias of these differences on the predictors of adverse outcomes, 917 patients from each group were propensity score matched. Their overall characteristics are shown in Table 2, indicating that both groups were well matched. 
TABLE 1. Overall preoperative characteristics in the study populations

\begin{tabular}{|c|c|c|c|}
\hline Variable & $\begin{array}{c}\text { White } \\
\text { patients, } \\
n=5028\end{array}$ & $\begin{array}{c}\text { South Asian } \\
\text { patients, } \\
n=1163\end{array}$ & $P$ value \\
\hline Male sex & $77.7 \%$ & $77.9 \%$ & NS \\
\hline Age (y) & $63.6 \pm 10$ & $\downarrow 60.8 \pm 9$ & $<.0001$ \\
\hline Body surface area $\left(\mathrm{m}^{2}\right)$ & $1.96 \pm 0.21$ & $\downarrow 1.80 \pm 0.18$ & $<.0001$ \\
\hline Family history & $68.1 \%$ & $\downarrow 54.4 \%$ & $<.0001$ \\
\hline NYHA class III or IV & $81.0 \%$ & $\uparrow 84.1 \%$ & $<.006$ \\
\hline Congestive heart failure & $9.6 \%$ & $8.1 \%$ & NS \\
\hline Unstable angina & $97.1 \%$ & $98.5 \%$ & NS \\
\hline Urgent/emergency operation & $47.2 \%$ & $52.0 \%$ & NS \\
\hline Redo CABG & $5.6 \%$ & $\downarrow 1.9 \%$ & $<.0001$ \\
\hline Left main disease & $21.7 \%$ & $\downarrow 7.8 \%$ & $<.003$ \\
\hline No. of diseased vessels $(\geq 3)$ & $76.3 \%$ & $79.2 \%$ & NS \\
\hline LV grade III or IV & $22.9 \%$ & $19.4 \%$ & NS \\
\hline Prior $\mathrm{MI}(>1 \mathrm{mo})$ & $21.6 \%$ & $25.7 \%$ & NS \\
\hline Diabetes & $24.8 \%$ & $\uparrow 45.4 \%$ & $<.0001$ \\
\hline Hypertension & $54.8 \%$ & $57.8 \%$ & NS \\
\hline Hyperlipidemia & $69.3 \%$ & $69.4 \%$ & NS \\
\hline Peripheral vascular disease & $17.7 \%$ & $\downarrow 10.7 \%$ & $<.0001$ \\
\hline
\end{tabular}

NS, Not significant; NYHA, New York Heart Association; CABG, coronary artery bypass grafting; $L V$, left ventricular; $M I$, myocardial infarction.

The perioperative and postoperative morbidity of the propensity score-matched patients are shown in Tables 3 and 4. Thus when the preoperative characteristics of the South Asian and white patients were propensity score

TABLE 2. Overall preoperative characteristics of the propensity score-matched South Asian and white patients

\begin{tabular}{lcc}
\hline Variable & $\begin{array}{c}\text { White patients, } \\
\mathbf{n = 9 1 7}\end{array}$ & $\begin{array}{c}\text { South Asian } \\
\text { patients, } \mathbf{n}=\mathbf{9 1 7}\end{array}$ \\
\hline Male sex & $76.5 \%$ & $76.4 \%$ \\
Age (y) & $61.5 \pm 11$ & $61.3 \pm 9$ \\
Body surface area $\left(\mathrm{m}^{2}\right)$ & $1.82 \pm 0.18$ & $1.82 \pm 0.19$ \\
Family history & $57.8 \%$ & $58.1 \%$ \\
NYHA class III or IV & $82.3 \%$ & $83.0 \%$ \\
Congestive heart failure & $8.2 \%$ & $8.5 \%$ \\
Unstable angina & $63.7 \%$ & $63.6 \%$ \\
Urgent/emergency operation & $50.0 \%$ & $51.0 \%$ \\
Redo CABG & $2.2 \%$ & $2.1 \%$ \\
Left main disease & $17.6 \%$ & $17.8 \%$ \\
No. of diseased vessels ( $\geq 3)$ & $78.5 \%$ & $77.5 \%$ \\
LV grade III or IV & $17.6 \%$ & $17.8 \%$ \\
Prior MI (>1 mo) & $23.8 \%$ & $22.4 \%$ \\
Diabetes & $37.3 \%$ & $39.4 \%$ \\
Hypertension & $56.7 \%$ & $52.3 \%$ \\
Hyperlipidemia & $68.5 \%$ & $68.5 \%$ \\
Peripheral vascular disease & $10.8 \%$ & $10.6 \%$ \\
\hline
\end{tabular}

There were no significant differences in preoperative characteristics in the propensity score-matched South Asian and white patients. NYHA, New York Heart Association; $C A B G$, coronary artery bypass grafting; $L V$, left ventricular; $M I$, myocardial infarction.
TABLE 3. Perioperative characteristics of the propensity score-matched South Asian and white populations

\begin{tabular}{lccc}
\hline Variable & $\begin{array}{c}\text { White } \\
\text { patients, } \\
\mathbf{n = 9 1 7}\end{array}$ & $\begin{array}{c}\text { South Asian } \\
\text { patients, } \\
\mathbf{n = 9 1 7}\end{array}$ & $\begin{array}{c}\boldsymbol{P} \\
\text { value }\end{array}$ \\
\hline Distal grafts & & & \\
$\quad 1$ & $1.9 \%$ & $1.0 \%$ & $\mathrm{NS}$ \\
2 & $9.4 \%$ & $7.8 \%$ & $\mathrm{NS}$ \\
$\quad 3$ & $88.8 \%$ & $91.1 \%$ & $\mathrm{NS}$ \\
LITA used & $91.0 \%$ & $88.9 \%$ & $\mathrm{NS}$ \\
CPB time (min \pm SD) & $84.5 \pm 29$ & $85.5 \pm 31$ & $\mathrm{NS}$ \\
Crossclamp time (min \pm SD) & $65.8 \pm 22$ & $62.7 \pm 21$ & $\mathrm{NS}$ \\
Ventilation Time (h \pm SD) & $13.3 \pm 49$ & $\uparrow 16.7 \pm 49$ & $<.001$ \\
ICU stay (h \pm SD) & $42.9 \pm 76$ & $\uparrow 48.2 \pm 66$ & $<.001$ \\
Postoperative stay (d \pm SD) & $7.2 \pm 5$ & $\uparrow 7.8 \pm 6$ & $<.001$ \\
\hline
\end{tabular}

LITA, Left internal thoracic artery; CPB, cardiopulmonary bypass; $S D$, standard deviation; ICU, intensive care unit.

matched for preoperative characteristics, significant differences still remained. The South Asian patients were ventilated longer after surgical intervention and remained longer in the intensive care unit and hospital.

Postoperatively, more South Asian patients had low output syndrome, MIs, and sternal wound infections than white patients. Consistent with previous studies, the incidence of stroke was similar, as were the incidences of pulmonary complications and renal failure.

In-hospital mortality also was significantly higher in South Asian patients than in white patients $(2.5 \%$ vs $1.1 \%, P=.02$.) The independent predictors of these adverse effects are shown in Table 5. Consistent with well-established data, increasing age, a history of unstable angina, hypertension, and a left ventricular ejection fraction of less than $40 \%$ were independent predictors of mortality. More importantly from the perspective of this study, being of South Asian origin also was an important predictor of mortality.

\section{Discussion}

A large number of patients successfully undergo CABG for cardiac revascularization each year. ${ }^{11}$ Nonetheless, a small

TABLE 4. Postoperative morbidity in the propensity scorematched South Asian and white patients

\begin{tabular}{lccc}
\hline Variable & $\begin{array}{c}\text { White } \\
\text { patients }\end{array}$ & $\begin{array}{c}\text { South Asian } \\
\text { patients }\end{array}$ & $\boldsymbol{P}$ value \\
\hline Low output syndrome & $5.3 \%$ & $\uparrow 7.7 \%$ & $<.05$ \\
MI & $2.6 \%$ & $\uparrow 4.3 \%$ & $<.05$ \\
Sternal wound infection & $1.4 \%$ & $\uparrow 2.7 \%$ & $<.005$ \\
Stroke & $1.3 \%$ & $1.0 \%$ & NS \\
Pulmonary complications & $6.5 \%$ & $7.2 \%$ & NS \\
Renal failure & $0.9 \%$ & $1.9 \%$ & NS \\
\hline
\end{tabular}

$M I$, Myocardial infarction; NS, not significant. 
TABLE 5. Independent predictors of mortality in South Asian and white patients

\begin{tabular}{lcc}
\hline Variable & Odds ratio & 95\% Confidence interval \\
\hline Increasing age & 1.1 & $1.05-1.15$ \\
Unstable angina & 1.9 & $1.2-3.0$ \\
Hypertension & 2.5 & $1.0-6.8$ \\
LVEF $<40 \%$ & 12.2 & $3.3-44.9$ \\
South Asian ethnicity & 3.1 & $1.4-6.8$ \\
\hline
\end{tabular}

$L V E F$, Left ventricular ejection fraction.

but significant number of these patients experience a variety of adverse side effects. Many of these side effects are associated with comorbid conditions, such as diabetes, hypertension, and hyperlipidemia. ${ }^{12}$ In addition, extraneous factors, such as lifestyle and environment, are thought to influence possible outcomes. The increasing evidence that ethnicity (ie, genetic make-up) also might influence atherosclerosis and CHD in general ${ }^{1-10}$ suggests that ethnicity itself should be factored in when assessing potential risks associated with assorted medical and surgical intervention procedures. This latter suggestion is controversial, given the perceived racial profiling concerns within our American and Canadian societies. In fact, our Canadian medical community is not allowed to record race in a patient's medical file. The observations of the current study challenge the prudence of that notion.

Specifically, we have provided solid evidence from a large number of patients that being of South Asian origin is a predictor of increased morbidity and mortality after cardiac surgery. These observations are consistent with previous studies that indicate that the incidence of CHD and atherosclerosis are higher in North American and European patients of South Asian origin. ${ }^{5,10}$

It is not surprising that the incidence of sternal wound infections is high in South Asian patients, given their higher diabetic and insulin-resistant comorbidities. ${ }^{1}$ As such, diabetes, insulin resistance, or both would be factored into their preoperative assessment. When these factors were propensity score matched, the incidence of sternal wound infections remained higher in South Asian patients than in white patients. These observations indicate that ethnicity per se exacerbates this adverse event.

Other studies suggest that there is a paradox in this regard. Specifically, it has been report that South Asian patients have less atherosclerosis than European patients but have a higher rate of cardiovascular disease. ${ }^{10}$ Those investigators suggested that differences in plasma lipid levels and glucose abnormalities affect differently the cause of cardiovascular events. They also found that South Asian ethnicity itself was a strong and independent determinant of these adverse events. Our study is not entirely consistent with those observations. Although we found overall that our
South Asian population had less of a CHD family history than our white population, more South Asian patients were identified as being in NYHA class III or IV. These observations indicated that the progression of atherosclerosis was at least comparable, if not worse, in the South Asian patients than in the white patients, particularly because the South Asian patients were significantly younger than the white population. It is possible that this difference is explained in part by the propensity score matching of a clearly defined patient treatment population. Although we cannot exclude the possibility that there are specific glucose abnormalities in our 2 patient groups, again our propensity score-matching approach factors out this possibility from ethnicity per se. In addition, it must be noted that mathematic propensity equilibration might not accurately reflect actual patient anatomy. The demographics of both patient groups suggest that the South Asian patients have a higher prevalence of diffuse distal disease than do white patients, which indeed could explain why South Asian patients appear to be at a higher risk. Hence it seems prudent that ethnicity should be recorded in each patient file and be recognized as a potential predictor (marker) of outcome after CABG and most likely of other interventional vascular procedures.

Finally, it should be noted that CABG is a successful and beneficial revascularization treatment for South Asian patients, despite the higher incidence of certain adverse side effects. However, a better understanding of the role of ethnicity in cardiovascular disease might help us to better optimize both patient preoperative assessment and postoperative management. The latter recommendation seems intuitively obvious because there is increasing evidence that the incidence of CHD and the risks of complicating risk factors appear to vary markedly among ethnic groups, including not only South Asian and white patients but also African American and Asian patients. ${ }^{1-10}$ Preoperative lipid and glucose abnormalities should be meticulously controlled to reduce postoperative morbidity in the South Asian population. In addition, given that more South Asian patients were identified as being in NYHA class III or IV, optimal hemodynamic support with inotropic agents or an intra-aortic balloon pump might decrease the incidence of postoperative low output syndrome or MI.

There are some potential limitations to our study. We might have excluded some South Asian and white patients because of nondefinitive names, thereby decreasing the number of patients analyzed, although this seems unlikely given our low error rate when identifying both white and South Asian patients. In addition, we cannot exclude the possibility that the apparent lack of a known CHD family history for some patients is because of poor documentation in their originating country.

We thank all the cardiovascular surgeons at the Toronto General Hospital for allowing us to access their patient files. We also 
thank Mr Geoffrey Sanz, a medical student who conducted a useful literature review of first and last name identification of ethnic origin.

\section{References}

1. Dhawan J, Bray CL, Warburton R, Chambhir DS, Morris J. Insulin resistance, high prevalence of diabetes, and cardiovascular risk in immigrant Asians. Genetic or environmental effect? Br Heart J. 1994; 72:413-21.

2. Chaturvedi N, Fuller JH. Ethnic differences in mortality from cardiovascular disease in the UK: do they persist in people with diabetes? $J$ Epidemiol Community Health. 1996;50:137-9.

3. Cappuccio FP. Ethnicity and cardiovascular risk: variations in people of African ancestry and South Asian origin. J Hum Hypertens. 1997; 11:571-6

4. Sheth T, Nair C, Nargundkar M, Anand S, Yusuf S. Cardiovascular and cancer mortality among Canadians of European, South Asian and Chinese origin from 1979 to 1993: an analysis of 1.2 million deaths. CMAJ. 1999;161:132-8.

5. Gupta M, Doobay AV, Singh N, Anand, Raja F, Mawji F, et al. Risk factors, hospital management and outcomes after acute myocardial infarction in South Asian Canadians and matched control subjects. CMAJ. 2002;166:717-22.

6. Greenhalgh PM. Diabetes in British South Asians: nature, nurture and culture. Diabet Med. 1997;14:10-8.

7. Kain K, Catto AJ, Grant PJ. Associations between insulin resistance and thrombotic risk factors in high risk South Asian subjects. Diabet Med. 2003;20:651-5.
8. Julan-Vague I, Alessi MC, Vague P. Thrombogenic and fibrinolytic factors and cardiovascular risk in non-insulin dependent diabetes mellitus. Ann Med. 1996;28:371-80.

9. Potts J, Simmons D. Sex and ethnic group differences in fat distribution in young United Kingdom South Asians and Europids. J Clin Epidemiol. 1994;47:837-41.

10. Anand S, Yusuf S, Vuksan V, Devanesen S, Teo KK, Montague PA, et al. for the SHARE Investigators. Differences in risk factors, atherosclerosis and cardiovascular disease between ethnic groups in Canada; the Study of Health Assessment and Risk in Ethnic groups (SHARE) Lancet. 2000;356:279-84.

11. RITA Trial Participants. Coronary angioplasty versus coronary artery bypass surgery: the randomized intervention treatment of angina (RITA) trial. Lancet. 1991;341:573-80.

12. O'Connor GT, Plume SK, Olmstead EM, Coffin LH, Morton JR, Malon $\mathrm{CT}$, et al. A regional prospective study of in-hospital mortality associated with coronary artery bypass grafting. The Northern New England Cardiovascular Disease Study Group. JAMA. 1992;267:932-3.

13. Bouwhuis CB, Moll HA. Determination of ethnicity in children in the Netherlands: two methods compared. Eur J Epidemiol. 2003;18:385-8.

14. Senior PA, Bhopal R. Ethnicity as a variable in epidemiological research. BMJ. 1994;309:327-30.

15. Nicoll A, Bassett K, Ulijaszek SJ. What's in a name? accuracy of using surnames and forenames in ascribing Asian ethnic identity in English populations. J Epidemiol Community Health. 1986;40:364-8.

16. SAS Institute. SAS/STAT user's guide, Version 8. Cary (NC): SAS Institute; 1988.

17. Parsons L. Reducing bias in a propensity score matched-pair sample using greedy matching techniques. In: Proceedings of the 26th Annual SAS Users Group International Conference. Cary (NC): SAS Institute; 2001. p. 214-26.

Access to The Journal of Thoracic and Cardiovascular Surgery Online is reserved for print subscribers!

Full-text access to The Journal of Thoracic and Cardiovascular Surgery Online is available for all print subscribers. To activate your individual online subscription, please visit The Journal of Thoracic and Cardiovascular Surgery Online, point your browser to http://www.mosby.com/itcvs, follow the prompts to activate your online access, and follow the instructions. To activate your account, you will need your subscriber account number, which you can find on your mailing label (note: the number of digits in your subscriber account number varies from 6 to 10 ). See the example below in which the subscriber account number has been circled:

\section{Sample mailing label}

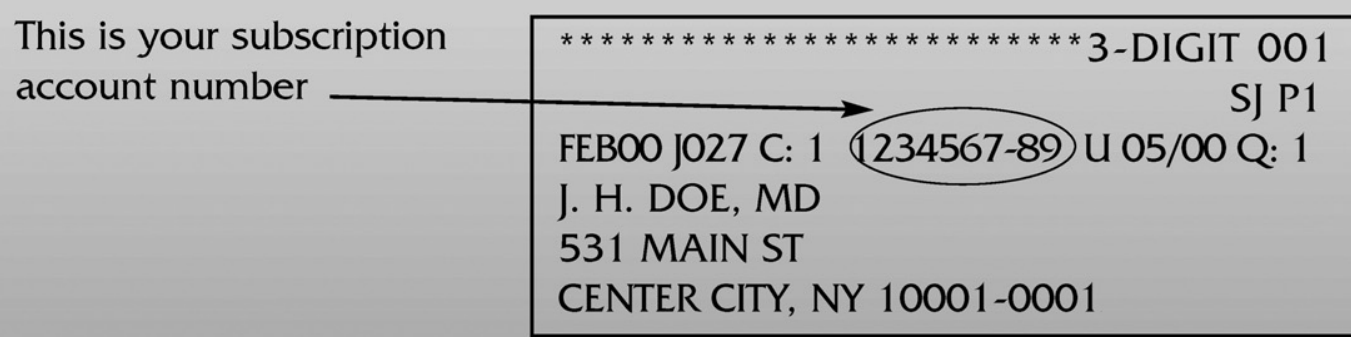

Personal subscriptions to The Journal of Thoracic and Cardiovascular Surgery Online are for individual use only and may not be transferred. Use of The Journal of Thoracic and Cardiovascular Surgery Online is subject to agreement to the terms and conditions as indicated online. 